Article

\title{
Improvement of Soybean Agrobacterium-Mediated Transformation Efficiency by Adding Glutamine and Asparagine into the Culture Media
}

\author{
Li Chen ${ }^{1,2,+}$, Yupeng Cai ${ }^{1,2,+}$, Xiujie Liu ${ }^{1,2}$, Weiwei Yao ${ }^{1,2}$, Chen Guo ${ }^{1,2}$, Shi Sun ${ }^{2}$, \\ Cunxiang $\mathrm{Wu}^{2}$, Bingjun Jiang ${ }^{2}$, Tianfu Han ${ }^{2}$ and Wensheng Hou ${ }^{1,2, *}$ \\ 1 National Center for Transgenic Research in Plants, Institute of Crop Sciences, Chinese Academy of \\ Agricultural Sciences, Beijing 100081, China; chenli01@caas.cn (L.C.); caiyupeng2015@126.com (Y.C.); \\ liuxiujie235@163.com (X.L.); yaoweiwei_nky@126.com (W.Y.); goldsion@163.com (C.G.) \\ 2 Ministry of Agriculture Key Laboratory of Soybean Biology (Beijing), Institute of Crop Sciences, \\ Chinese Academy of Agricultural Sciences, Beijing 100081, China; sunshi@caas.cn (S.S.); \\ wucunxiang@caas.cn (C.W.); jiangbingjun@caas.cn (B.J.); hantianfu@caas.cn (T.H.) \\ * Correspondence: houwensheng@caas.cn; Tel.: +86-10-8210-5172 \\ + These authors contributed equally to this work.
}

Received: 5 September 2018; Accepted: 1 October 2018; Published: 5 October 2018

\begin{abstract}
As a genetically modified crop, transgenic soybean occupies the largest global scale with its food, nutritional, industrial, and pharmaceutical uses.Efficient transformation is a key factor for the improvement of genetically modified soybean. At present, the Agrobacterium-mediated method is primarily used for soybean transformation, but the efficiency of this method is still relatively low (below 5\%) compared with rice (above 90\%). In this study, we examined the influence of L-glutamine and/or L-asparagine on Agrobacterium-mediated transformation in soybean and explored the probable role in the process of Agrobacterium-mediated transformation. The results showed that when the amino acids L-glutamine and L-asparagine were added separately or together to the culture medium, the shoot induction frequency, elongation rate, and transformation frequency were improved. The combined effects of L-glutamine and L-asparagine were better than those of L-glutamine and L-asparagine alone. The $50 \mathrm{mg} / \mathrm{L}$ L-glutamine and $50 \mathrm{mg} / \mathrm{L}$ L-asparagine together can enhance the transformation frequency of soybean by attenuating the expression level of GmPRs (GmPR1, GmPR4, GmPR5, and GmPR10) and suppression of the plant defense response. The transgene was successfully transmitted to the T1 generation. This study will be useful in genetic engineering of soybean.
\end{abstract}

Keywords: soybean; Agrobacterium-mediated transformation; L-asparagine; L-glutamine; transformation frequency

\section{Introduction}

Soybean (Glycine $\max (\mathrm{L}$.) Merrill) is one of the world's most important oil and protein crops, serving as a food source for humans and for animal forage, and it has industrial uses [1]. Transgenic soybean is a genetically modified (GM) crop that occupies the largest global scale with its food, nutritional, industrial, and pharmaceutical uses. From 1996 to 2015, approximately 1030 million hectares of GM soybean were planted and more than 50 billion US dollars were generated as income to farmers. In 2015, approximately 92.1 million hectares of GM soybean were planted around the world in 11 countries, which accounted for $51 \%$ of all GM crop hectares and $83 \%$ of the soybean grown all over the world [2]. 
Valuable genes and efficient transformation are the key factors for the improvement of GM soybean. As rice varieties are becoming more popular model plants, research on soybeantransgenic lines and the improvement of soybean agronomic characteristics has fallen behind, and that may be possibly due to genome complexity and the lower transformation efficiency [3].

A new technology for genome editing-the CRISPR (clustered regularly interspaced short palindromic repeat)/Cas (CRISPR-associated) system-has been successfully used for genome engineering in many important crops in recent years [4-12]. Since 2015, CRISPR/Cas9-mediated genome editing in soybean has shown an initial success [13-19]. This technology provides a powerful tool for accurate genetic modification and gene function identification, but it also relies on transformation efficiency.

Soybean transformation was first reported in 1988 using an Agrobacterium tumefaciens infection with cotyledonary node plant regeneration [20] or by particle bombardment of the meristems of immature seeds [21]. Over more than 20 years, these two methods have been continually improved and developed, and Agrobacterium-mediated transformation remains the method of choice in soybean.

Many factors are known to affect the efficiency of T-DNA delivery to the plant cell. The factors influencing Agrobacterium-mediated transformation efficiency include the Agrobacterium strain, Agrobacterium inoculation density, explant types, genome, inoculation period, culture medium, and selection system, among others [22,23]. According to these factors, much effort has been made to enhance the efficiency of soybean transformation: the utilization of different explants, such as the cotyledonary node, hypocotyls, embryonic tip, half-seed, and immature seed [24-27]; different selection agents, such as glufosinate, glyphosate, and hygromycin [28-30]; supplementation with amino acids or antioxidants, such as dithiothreitol, L-cysteine, and sodium thiosulfate [30,31], among others [32,33].

It has been reported that the addition of L-glutamine into culture medium alone or in combination with a cold shock pretreatment could enhance Agrobacterium transformation efficiency [34]. L-Glutamine was also found to inhibit $\beta$-aminobutyric acid (BABA)-induced plant resistance to a bacterial pathogen of Arabidopsis [35]. The metabolism of glutamine has been implicated in the plant response to pathogen infection [36]. The molecular mechanisms by which glutamine affects plant defence responses are still poorly understood, but the results suggest that L-glutamine could play a role in lessening host defence responses by attenuating the expression of certain pathogenesis-related genes (PRs) and potentially improve the efficiency of Agrobacterium-mediated plant transformation [34,37].

In the present study, we examined the influence of L-glutamine and/or L-asparagine on Agrobacterium-mediated transformation in soybean and explored the probable role of L-glutamine and/or L-asparagine during the process of Agrobacterium-mediated transformation. We designed experiments to: determine the effects of L-glutamine and/or L-asparagine, which were added to the co-cultivation medium (CCM), recovery medium (SIM0), selection medium (SIM6), shoot elongation medium (SEM), and rooting culture medium (RCM), on shoot regeneration and elongation; to investigate if these modified media could attenuate plant defense response, enhance the transformation frequency, and further contribute to a wider range of soybean genotypes, and also; to investigate the transmission of the transgene to the $\mathrm{T} 1$ generation.

\section{Results}

\subsection{L-Asparagine and L-Glutamine Improved the Shoot Induction Frequency and Increased the Frequency of Highly-Expressing Transgene (GUS) Shoots}

The cultivar Jack, routinely used in soybean transformation for its relatively high transformation frequency between $3.5-5.5 \%$, was selected to test the treatments. After co-cultivation and recovery, the explants were placed on selection medium, and induced multiple shoots at the growing point of the cotyledon and hypocotyls. The shoot induction frequency was approximately $68.9 \%$ when no L-asparagine or L-glutamine was added to the media, and the shoot induction frequencies were approximately $77.9 \%$ and $84.3 \%$ in media supplemented with L-asparagine or L-glutamine, respectively. 
The frequency was enhanced by $10-15 \%$ in media supplemented with L-asparagine or L-glutamine. The shoot induction frequency was above $90 \%$ when media was supplemented with both L-asparagine and L-glutamine. Compared with no L-asparagine or L-glutamine was added to the media, the frequency was enhanced remarkably when media was supplemented with both L-asparagine and L-glutamine (Table 1).

Table 1. Shoot induction frequenciesofthe different treatments.

\begin{tabular}{lccc}
\hline \multicolumn{1}{c}{ Treatment } & No. of Explants & No. of Explants with Shoots & Shoot Induction Frequency (\%) \\
\hline (-) no supplemental L-amino acid & 390 & 270 & $68.9 \pm 2.0^{\mathrm{d}}$ \\
(+) L-asparagine & 407 & 316 & $77.9 \pm 2.0^{\mathrm{c}}$ \\
(+) L-glutamine & 358 & 304 & $84.3 \pm 1.3^{\mathrm{b}}$ \\
(+) L-asparagine and L-glutamine & 431 & 400 & $92.5 \pm 2.6^{\mathrm{a}}$ \\
\hline
\end{tabular}

Three independent experiments were performed for each treatment. No. of explants: the total number of explants for the three experiments; No. of explants with shoots: the total number of explants produced shoots for the three experiments. The explants with shoots were defined as the shoots with green leaves after 21 days transferred to selection media. The shoot induction frequency is expressed as the mean \pm standard deviation. The different small letters represent significant differences between treatments by ANOVA $(p<0.05)$. $(-)$ represents no L-amino acid added into the media. $(+)$ represents L-amino acid added into the media.

All evaluations in transformed soybean plants were conducted using the expression cassette which encodes for a GUS reporter gene and Bar resistance gene for selection. The reporter transgene expression (GUS) of multiple shoots was tested and classified according to staining intensity as measured by ELISA. According to the GUS activity, the GUS staining was classified into four classes: negative $(-)$ (Figure 1a-d), the GUS activity was below $0.45 \mathrm{U} / \mathrm{g}$; low $(+)$ (Figure 1e-h), the GUS activity was around 0.45 to $0.6 \mathrm{U} / \mathrm{g}$; medium $(++)$ (Figure $1 \mathrm{i}-1$ ), the GUS activity was around 0.6 to $0.7 \mathrm{U} / \mathrm{g}$; and high (+++) (Figure $1 \mathrm{~m}-\mathrm{p}$ ), the GUS activity was around 0.7 to $0.8 \mathrm{U} / \mathrm{g}$. For each treatment, 30 shoots were evaluated for GUS staining as classified in Figure 1 and GUS activity as measured by ELISA.

As shown in Table 2, in the presence of L-aspargine the percentage of GUS activity was $66.7 \%$, while in the presence of L-glutamine activity rose to $70 \%$, in comparison to shoots in the absence of L-amino acids tested. In the presence of L-asparagine and L-glutamine overall levels of GUS-positive shoots was $70 \%$. It suggested that L-asparagine and L-glutamine could increase the frequency of highly-expressing GUS shoots.

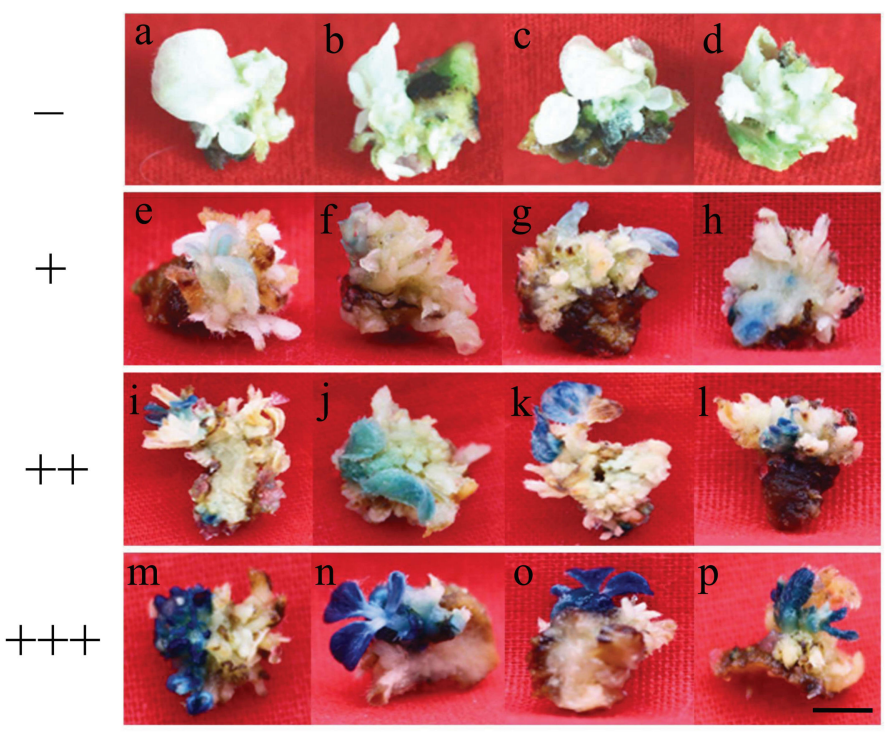

Figure 1. The fourclasses of multiple shoots for transgene (GUS) staining. (a-d)“_"Representation of negative; $(\mathbf{e}-\mathbf{h})^{\text {“ }}+$ " representation of low dyeing; $(\mathbf{i}-\mathbf{l})^{\prime \prime}++{ }^{\prime \prime}$ representation of medium dyeing; $(\mathbf{m}-\mathbf{p})^{\prime \prime}+++"$ representation of high dyeing. Scale bar, $1 \mathrm{~cm}$. 
Table 2. Expression ofmultiple shoots as determined by GUS staining and GUS activity.

\begin{tabular}{|c|c|c|c|c|c|c|}
\hline \multirow[b]{2}{*}{ Treatment } & \multicolumn{5}{|c|}{ No. of Shoots in the Different Degrees of Gus Staining (Percentage, \%) } & \multirow{2}{*}{$\begin{array}{l}\text { No. of Total } \\
\text { GUS-Positive Shoots a } \\
\text { (Percentage, \%) }\end{array}$} \\
\hline & $\begin{array}{l}\text { GUS StainingGUS } \\
\text { Activity (U/g) }\end{array}$ & $-(0-0.45)$ & $+(0.45-0.6)$ & $++(0.6-0.7)$ & $+++(0.7-0.8)$ & \\
\hline \multicolumn{2}{|c|}{ (-) no supplemental L-amino acid } & $18(60.0)$ & $5(16.7)$ & $5(16.7)$ & $2(6.6)$ & $12(40.0)$ \\
\hline \multicolumn{2}{|l|}{$(+)$ L-asparagine } & $10(33.3)$ & $8(26.7)$ & $6(20.0)$ & $6(20.0)$ & $20(66.7)$ \\
\hline \multicolumn{2}{|l|}{ (+) L-glutamine } & $9(30.0)$ & $11(36.7)$ & $7(23.3)$ & $3(10.0)$ & $21(70.0)$ \\
\hline \multicolumn{2}{|c|}{ (+) L-asparagine and L-glutamine } & $9(30.0)$ & $3(10.0)$ & $6(20.0)$ & $12(40.0)$ & $21(70.0)$ \\
\hline
\end{tabular}

For each treatment, 30 shoots was for GUS staining. - : negative, GUS activity was below 0.45 U/g; +: low GUS staining, GUS activity was around 0.45 to $0.6 \mathrm{U} / \mathrm{g}$; ++: medium GUS staining, GUS activity was around 0.6 to $0.7 \mathrm{U} / \mathrm{g}$; +++: high GUS staining, GUS activity was around 0.7 to $0.8 \mathrm{U} / \mathrm{g}$. $0.1 \mathrm{~g}$ tissues were used to measure GUS activity by ELISA Kit. The GUS activity $(\mathrm{U} / \mathrm{g})$ is determined by comparing the Optical Density of the samples to the standard curve generated from standard with kit. Percentage $\%=$ No. of shoots in each class $/$ total number $\times 100 \%$.

a Total GUS-positive shoots means the shoots with GUS staining, including,+++ and +++. (-) represents no L-amino acid added into the media. (+) represents L-amino acid added into the media.

\subsection{L-Asparagine and L-Glutamine Improved the Elongation Efficiency and Prolonged Transfer for Shoot Elongation (SE)}

After selecting for shoot induction, the explants produced multiple herbicide-resistant buds. The multiple buds without cotyledons were transferred to the shoot elongation medium (SEM) and subcultured for 3-5 times. Therefore, we recorded the number of elongated plants cultured every time (Table 3). When the media with no L-asparagine or L-glutamine added, $28.4 \%$ of the elongated shoots were produced in the first time (SE1); $37.8 \%$ and $33.8 \%$ of the elongated shoots were produced in the second and third times (SE2 and SE3), respectively. There were no elongated shoots in the fourth and fifth times (SE4 and SE5). When the media was supplemented with L-asparagine, $34.6 \%$ of the elongated shoots were produced in SE1; $43.8 \%$ and $19.1 \%$ of the elongated shoots were produced in SE2 and SE3, respectively. Only $2.5 \%$ of the elongated shoots were produced in SE4. When the media was supplemented with L-glutamine, $13.8 \%, 37.1 \%, 34.5 \%, 11.2 \%$, and $3.4 \%$ of the elongated shoots were produced in SE1-SE5, respectively. When both L-asparagine and L-glutamine were added to the media, $13.3 \%, 57.7 \%, 19.5 \%$, and $9.5 \%$ of the elongated shoots were produced in SE1-SE4, respectively.

Table 3. No. of elongated shoots at different times and elongation rates in the different treatments.

\begin{tabular}{|c|c|c|c|c|c|c|c|c|}
\hline \multirow{2}{*}{ Treatment } & \multirow{2}{*}{$\begin{array}{c}\text { No. } \\
\text { of Explants }\end{array}$} & \multicolumn{6}{|c|}{ No. of Elongated Plants (Percentage, \%) } & \multirow{2}{*}{$\begin{array}{l}\text { Elongation } \\
\text { Rate } \%\end{array}$} \\
\hline & & Total & SE1 & SE2 & SE3 & SE4 & SE5 & \\
\hline $\begin{array}{l}(-) \text { no supplemental } \\
\text { L-amino acid }\end{array}$ & 390 & 74 & $21(28.4)$ & $28(37.8)$ & $25(33.8)$ & - & - & $20.2 \pm 5.6^{b}$ \\
\hline (+) L-asparagine & 407 & 162 & $56(34.6)$ & $71(43.8)$ & $31(19.1)$ & $4(2.5)$ & - & $39.8 \pm 1.9^{a b}$ \\
\hline (+) L-glutamine & 358 & 116 & $16(13.8)$ & $43(37.1)$ & $40(34.5)$ & $13(11.2)$ & $4(3.4)$ & $26.6 \pm 11.1^{\mathrm{ab}}$ \\
\hline $\begin{array}{l}\text { (+) L-asparagine and } \\
\text { L-glutamine }\end{array}$ & 431 & 180 & $24(13.3)$ & $104(57.7)$ & 35 (19.5) & $17(9.5)$ & - & $41.6 \pm 18.2^{\mathrm{a}}$ \\
\hline \multicolumn{9}{|c|}{$\begin{array}{l}\text { Three independent experiments were performed for each treatment. No. of explants: the total number of explants } \\
\text { for the three experiments; No. of elongated plants: the total number of elongated plants for the three experiments. } \\
\text { SE1: the first time; SE2: the second time; SE3: the third time; SE4: the fourth time; SE5: the fifth time. } \\
\text { Percentage } \%=\text { No. of elongated shoots produced at a specific time/Total number } \times 100 \% \text {. The elongation rate is } \\
\text { expressed as the mean } \pm \text { standard deviation. The different small letters represent significant differences between } \\
\text { treatments by ANOVA }(p<0.05) .(-) \text { represents no L -amino acid added into the media. }(+) \text { represents L-amino acid } \\
\text { added into the media. }\end{array}$} \\
\hline
\end{tabular}

At this stage, after the length of the shoots had elongated to more than $4 \mathrm{~cm}$, the shoots were cut from the multiple buds and then transferred for rooting. The more elongated shoots available, the more transgenic plants can be cultured. Table 3 shows the total number of elongated plants and the elongation rate. When the media with no L-asparagine or L-glutamine added, the elongation rate was approximately $20.2 \%$. When the media was supplemented with L-asparagine or L-glutamine, the elongation rate was approximately $39.8 \%$ and $26.6 \%$, respectively. When both L-asparagine and L-glutamine were added to the media, it was evidently enhanced and reached to $41.6 \%$. It suggested 
that when supplemented with either L-asparagine, L-glutamine or in combination, the elongation rates were significantly higher than in the absence of the L-amino acids.

\subsection{L-Asparagine and L-Glutamine Improved the Transformation Frequency}

We cut leaves from the elongated shoots to detect the positive shoots, and verification was performed using GUS staining, PAT strips and leaf painting (Figure 2). Strips were used to determine the presence of PAT protein of transgenic plants, and leaf painting was used to check the resistance of bar gene. When the media with no L-asparagine or L-glutamine added, 74 elongated shoots were detected, and among them, 12 shoots tested positive by PAT strips. The positive rate of the elongated shoots was approximately $16.2 \%$. The positive shoots were $14.8 \%$ and $36.0 \%$ in media supplemented with L-asparagine or L-glutamine, respectively. 46 of 180 elongated shoots were tested positive, and the positive rate of the elongated shoots was approximately $30.2 \%$ in when media was supplemented with both L-asparagine and L-glutamine (Table 4). The leaf painting and GUS staining were performed in order to corroborate results between the two methods and there was no difference between methods, so only PAT results are presented in Table 4.

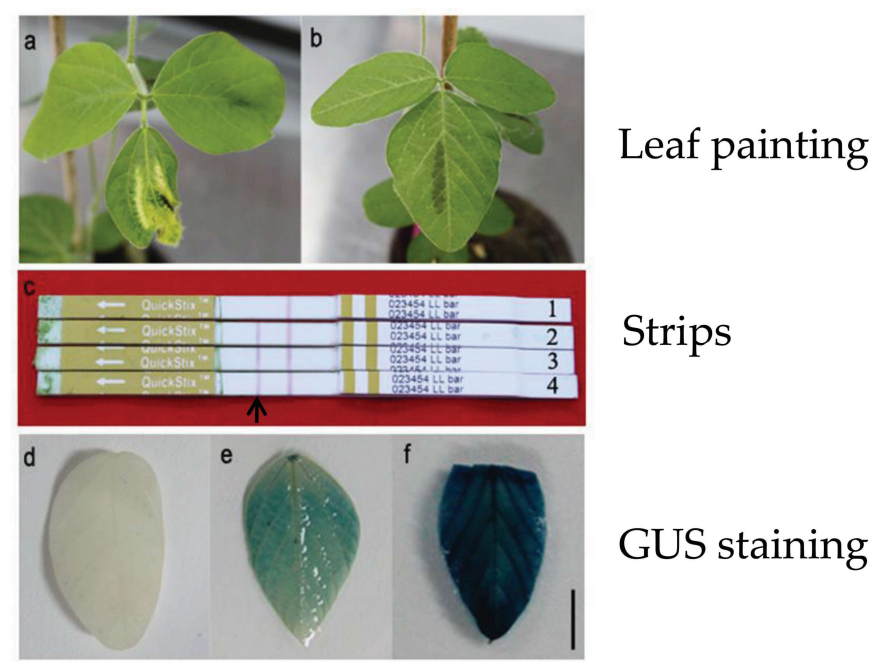

Figure 2. Detection of transgenic plants. (a) Negative plants by leaf painting; (b) Positive plants by leaf painting; (c) Strips detection: 1 Negative plant, 2-4 Positive plants, the bands at black arrowhead indicate that bar is positive; (d) Negative plants by GUS staining;(e,f) Positive plants by GUS staining. Scale bar, $1 \mathrm{~cm}$.

Table 4. Detection of elongated plants and transformation frequency for the different treatments.

\begin{tabular}{|c|c|c|c|c|c|}
\hline Treatment & $\begin{array}{c}\text { No. } \\
\text { of Explants }\end{array}$ & $\begin{array}{c}\text { No. of } \\
\text { Elongated Plants }\end{array}$ & $\begin{array}{c}\text { No. of } \\
\text { Positive Plants }\end{array}$ & $\begin{array}{c}\text { Positive Rate of } \\
\text { Elongated Plants (\%) }\end{array}$ & $\begin{array}{l}\text { Transformation } \\
\text { Efficiency (\%) }\end{array}$ \\
\hline $\begin{array}{l}(-) \text { no supplemental } \\
\text { L-amino acid }\end{array}$ & 390 & 74 & 12 & $16.2 \pm 6.8^{b}$ & $3.5 \pm 2.4^{c}$ \\
\hline$(+)$ L-asparagine & 407 & 162 & 22 & $14.8 \pm 4.8^{b}$ & $5.9 \pm 2.1^{b, c}$ \\
\hline (+) L-glutamine & 358 & 116 & 32 & $36.0 \pm 11.6^{\mathrm{a}}$ & $8.8 \pm 1.5^{\mathrm{a}, \mathrm{b}}$ \\
\hline $\begin{array}{l}\text { (+) L-asparagine } \\
\text { and L-glutamine }\end{array}$ & 431 & 180 & 46 & $30.2 \pm 14.9^{a, b}$ & $11.1 \pm 2.7^{a}$ \\
\hline
\end{tabular}

Each treatment has three independent experiments. No. of infected explants: the total number of infected explants for the three experiments; No. of elongated explants: the total number of elongated explants for the three experiments. No. of positive plants: the total number of plants with PAT strips ${ }^{+}$. Positive rate of elongated plants $\%=$ No. of positive plants $/$ No. of elongated explants $\times 100 \%$. The transformation frequency $\%=$ the No. of positive plants/No. of infected explants $\times 100 \%$. The Positive rate of elongated plants and transformation frequency are expressed as the mean \pm standard deviation. The different small letters represent significant differences between treatments by ANOVA $(p<0.05)$. (-) represents no L-amino acid added into the media. $(+)$ represents L-amino acid added into the media. ${ }^{+}$represents positive. 
From the detection of the elongated shoots, we calculated the transformation frequency. As shown in Table 4 , the transformation frequency was approximately $3.5 \%$ with no L-asparagine or L-glutamine was added to the media. The transformation frequency values were approximately $5.9 \%$ and $8.8 \%$ in media supplemented with L-asparagine or L-glutamine, respectively. The transformation frequency reached $11.1 \%$ in when media was supplemented with both L-asparagine and L-glutamine. The results indicated that L-asparagine and L-glutamine could remarkably enhanced transformation frequency.

\subsection{The Transformation Frequency in Four Soybean Cultivars Utilizing the New Conditions}

According to the results of the different treatments, the transformation frequency was the highest when media was supplemented with both L-asparagine and L-glutamine for cultivar Jack. Four soybean cultivars Jack, Williams 82 (standard cultivar), Zigongdongdou (early-maturity cultivar) and Heihe 27 (late-maturity cultivar) were infected with Agrobacterium and cultured on the improved medium supplemented with both L-asparagine and L-glutamine. The media with no L-asparagine or L-glutamine was the control. Shoots were regenerated with $6 \mathrm{mg} / \mathrm{L}$ glufosinate for all four cultivars. Under the new media supplemented with both L-asparagine and L-glutamine, the shoot induction frequency in Jack reached $92.3 \%$, and in Williams 82 and Heihe 27, it was above $85 \%$. The shoot induction frequency was approximately $62.7 \%$ in Zigongdongdou. Compared with the media with no L-asparagine or L-glutamine, the shoot induction frequency was enhanced in all cultivars tested. In addition, the transformation frequency was also improved. The transformation frequency in Jack was the highest. In Williams 82 and Heihe27, the transformation frequency was above $8 \%$. It was lower in Zigongdongdou (Table 5). The results demonstrated that the improved conditions can be applied to more soybean cultivars.

Table 5. Shoot induction frequency and transformation frequency in four soybean cultivars.

\begin{tabular}{lcccc}
\hline \multirow{2}{*}{ Genotype } & \multicolumn{2}{c}{ Shoot Induction Frequency (\%) } & \multicolumn{2}{c}{ Transformation Frequency (\%) } \\
\cline { 2 - 5 } & $\begin{array}{c}\text { (-) No Supplemental } \\
\text { L-Amino Acid }\end{array}$ & $\begin{array}{c}\mathbf{( + ) ~ L - A s p a r a g i n e ~}_{\text {and L-Glutamine }} \\
\text { and }\end{array}$ & $\begin{array}{c}\text { (-) No Supplemental } \\
\text { L-Amino Acid }\end{array}$ & $\begin{array}{c}\text { (+) L-Asparagine } \\
\text { and L-Glutamine }\end{array}$ \\
\hline Jack & $81.7 \pm 3.8^{\mathrm{b}}$ & $92.3 \pm 1.2^{\mathrm{a}}$ & $5.5 \pm 0.6^{\mathrm{b}}$ & $11.1 \pm 2.9^{\mathrm{a}}$ \\
Zigongdongdou & $56.3 \pm 4.3^{\mathrm{a}}$ & $62.7 \pm 3.4^{\mathrm{a}}$ & $1.3 \pm 0.2^{\mathrm{a}}$ & $2.6^{\mathrm{a}} \pm 1.3^{\mathrm{a}}$ \\
Williams82 & $81.6 \pm 1.5^{\mathrm{b}}$ & $86.8 \pm 1.5^{\mathrm{a}}$ & $4.4 \pm 0.7^{\mathrm{b}}$ & $8.3 \pm 1.9^{\mathrm{a}}$ \\
Heihe27 & $79.0 \pm 2.0^{\mathrm{b}}$ & $85.7 \pm 2.6^{\mathrm{a}}$ & $4.9 \pm 1.2^{\mathrm{a}}$ & $8.2^{\mathrm{a}} \pm 1.8^{\mathrm{a}}$ \\
\hline
\end{tabular}

Three independent experiments were performed for each genotype. The shoot induction frequency and transformation frequency were expressed as the mean \pm standard deviation. The different small letters represent significant differences between treatments by ANOVA $(p<0.05)$. $(-)$ represents no L-amino acid added into the media. (+) represents L-amino acid added into the media.

\subsection{Analysis of T1 Plants}

Five independent $\mathrm{T} 0$ transformants of each treatment were randomly selected, and the T1 plants from the five independent $\mathrm{T} 0$ transformants were examined for the presence of the bar gene by PCR. Some PCR detection results were showed in Figure 3. The plants were positive by presence of the amplified fragment of $427 \mathrm{bp}$, and the negative plants were not amplified in any fragment (Figure 3). The T1 plants were also examined the segregation ratios by Chi-square analysis (Table 6). The results indicated that only three lines (line 1, line 7, line 17) showed a 3:1 ratio $\left(\right.$ bar $^{+}:$bar $\left.{ }^{-}\right)$, and other lines were not fit to this ratio. We further confirmed the copy number of T1 transgenic plants (line 1-1, line 7-5, line 17-2, line 17-9) using Southern blot. The results showed the T1 plants in these three T0 lines had only one copy of the bar gene (Figure 4). 


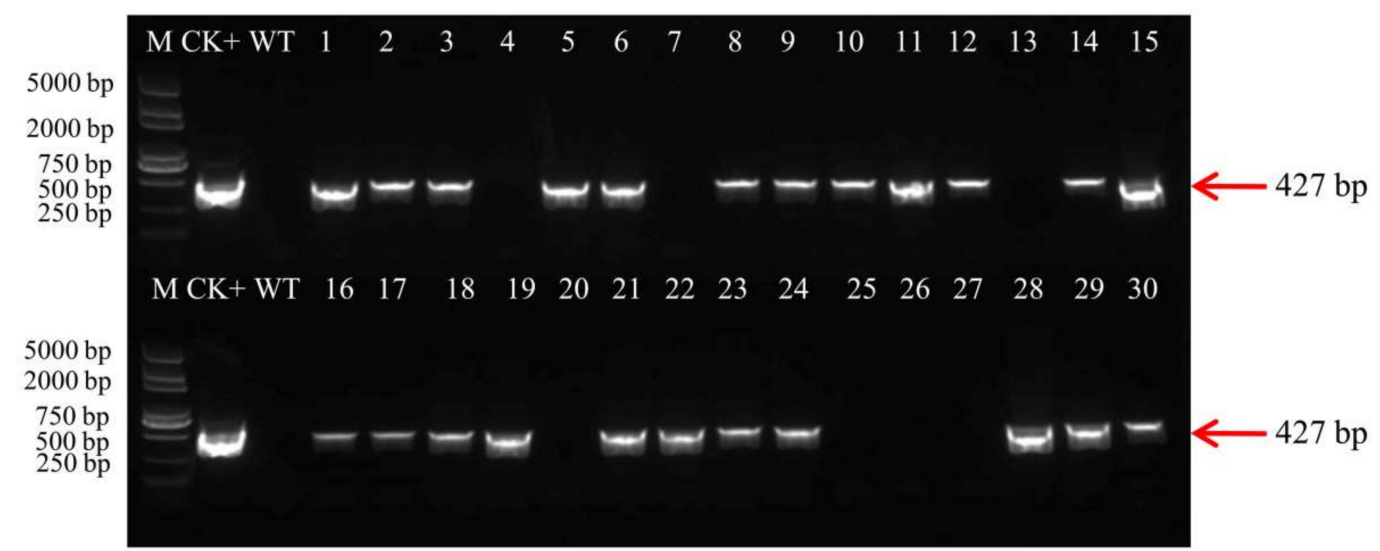

Figure 3. Detection of $\mathrm{T} 1$ transgenic plants by PCR. PCR analysis of genomic DNA of T1 transgenic plants using bar gene primers. The length of PCR product is $427 \mathrm{bp}$. M: DL2000 Plus; CK+: plasmid DNA; WT: wild-type soybean plant; lanes 1-7: T1 lines (line 1-1, line 1-2, line 2-1, line 3-1, line 3-3, line 3-4, line 4-1) versus 1-4 T0 lines from treatment without L-amino acid;lanes 8-15: T1 lines (line 6-1, line 6-2, line 7-1, line 7-2, line 7-3, line 7-4, line 7-5, line 8-1) versus 6-8 T0 lines from treatment with L-asparagine;lanes16-20: T1 lines (line 11-1, line 12-3, line 13-2, line 14-5, line 15-1)versus 11-15 T0 lines from treatment with L-glutamine;lanes21-30: T1 lines(line 16-1, line 17-1, line 17-2, line 17-9, line 17-10, line 17-11, line 17-12, line 17-14, line 18-5, line 19-10) versus 16-19 T0 lines from treatment with both L-asparagine and L-glutamine).

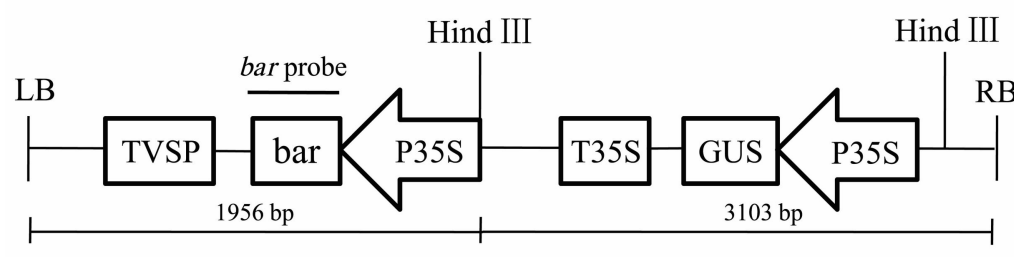

PTF102

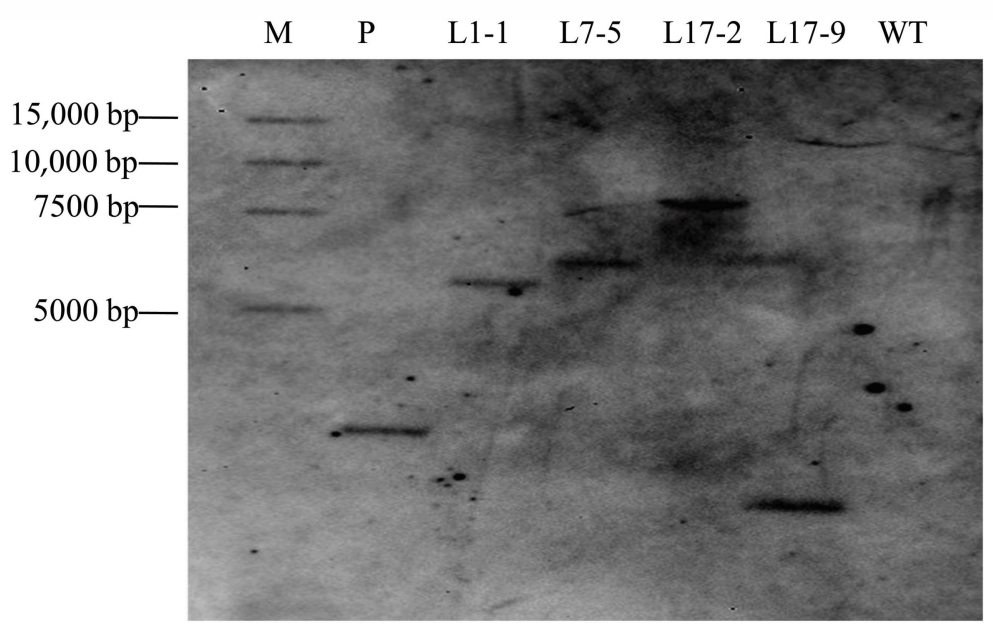

Figure 4. Southern blot analysis of T1 transgenic plants. Plasmid and genomic DNA were digested with HindIII, and hybridized with the bar probe labeled with DIG. M: marker; P: plasmid DNA of pWMB123; L1-1: DNA from T1 plant with $\mathrm{bar}^{+}$from transgenic line 1; L7-5: DNA from T1 plant with $\mathrm{bar}^{+}$from transgenic line 7; L17-2 and L17-9: DNA from T1 plant with bar ${ }^{+}$from transgenic line 17. WT: DNA from nontransgenic plants. 
Table 6. Segregation of bar gene in the T1 plants for the different treatments.

\begin{tabular}{|c|c|c|c|c|c|c|c|}
\hline \multirow{2}{*}{ Treatment } & \multirow{2}{*}{ T0 Lines } & \multirow{2}{*}{ No. of T1 Plants } & \multicolumn{5}{|c|}{ Segregation Pattern } \\
\hline & & & bar $^{+}$ & bar ${ }^{-}$ & Ratio & $x^{2}$ & $p$-Value \\
\hline \multirow{5}{*}{$\begin{array}{l}(-) \text { no supplemental } \\
\text { L-amino acid }\end{array}$} & 1 & 40 & 29 & 11 & $3: 1$ & 0.1333 & 0.7150 \\
\hline & 2 & 12 & 11 & 1 & - & - & - \\
\hline & 3 & 11 & 9 & 2 & - & - & - \\
\hline & 4 & 40 & 0 & 40 & - & - & - \\
\hline & 5 & 13 & 0 & 13 & - & - & - \\
\hline \multirow{5}{*}{ (+) L-asparagine } & 6 & 50 & 13 & 37 & - & - & - \\
\hline & 7 & 36 & 28 & 8 & $3: 1$ & 0.1481 & 0.7003 \\
\hline & 8 & 45 & 42 & 3 & - & - & - \\
\hline & 9 & 30 & 0 & 30 & - & - & - \\
\hline & 10 & 50 & 2 & 48 & - & - & - \\
\hline \multirow{5}{*}{$(+)$ L-glutamine } & 11 & 17 & 15 & 2 & - & - & - \\
\hline & 12 & 14 & 13 & 1 & - & - & - \\
\hline & 13 & 40 & 13 & 27 & - & - & - \\
\hline & 14 & 35 & 1 & 34 & - & - & - \\
\hline & 15 & 25 & 0 & 25 & - & - & - \\
\hline \multirow{5}{*}{$\begin{array}{l}\text { (+) L-asparagine and } \\
\text { L-glutamine }\end{array}$} & 16 & 13 & 10 & 3 & - & - & - \\
\hline & 17 & 40 & 31 & 9 & $3: 1$ & 0.1333 & 0.7150 \\
\hline & 18 & 10 & 1 & 9 & - & - & - \\
\hline & 19 & 20 & 1 & 19 & - & - & - \\
\hline & 20 & 15 & 0 & 15 & - & - & - \\
\hline
\end{tabular}

Each T0 line represents an independent transformant. T0 lines (1-5) from treatment without L-asparagine and L-glutamine; T0 lines (6-10) from treatment with L-asparagine; T0 lines (11-15) from treatment with L-glutamine; T0 lines (16-20) from treatment with both L-asparagine and L-glutamine. No. of T1 plants: the number of seeds from each T0 line. Three lines (line 1, line 7, line 17) showed a 3:1 ratio $\left(b a r^{+}: b_{a r}^{-}\right)$.Lines which were not fit to this ratio were represented by "-". (-) represents no L-amino acid added into the media. (+) represents L-amino acid added into the media.

Next, the seeds collected from all the other T0 transformants were planted and tested. If only one of the T1 plants was detected positive which was confirmed both by PCR and strip, we considered the T0 transformant was inherited to $\mathrm{T} 1$ generation. We determined that $66.7 \%$ (8 out of 12 ) in treatment with no L-asparagine or L-glutamine, $68.2 \%$ (15 out of 22 ) in treatment with only L-asparagine, $71.9 \%$ (23 out of 32) in treatment with only L-glutamine, and 73.9\% (34 out of 46) in treatment with both L-asparagine and L-glutamine bar positive T0 transformants had inherited in T1 plants, respectively (Table 7). Some of the T0 transformants in different treatments did not produce positive plants in T1 plants. Transgene positive T0 soybean plants did not necessarily pass the transgene to the next generation. There was no obvious difference in inheritance frequency between treatments. This indicated that L-asparagine and L-glutamine could not improve chimera.

Table 7. Inheritance frequency of T0 transformants for the different treatments.

\begin{tabular}{|c|c|c|c|}
\hline Treatment & No. of T0 Transformants & No. of Inheritance Transformants & $\begin{array}{c}\text { Inheritance } \\
\text { Frequency (\%) }\end{array}$ \\
\hline $\begin{array}{l}\text { (-) no supplemental } \\
\text { L-amino acid }\end{array}$ & 12 & 8 & $66.7 \pm 25.5^{\mathrm{a}}$ \\
\hline$(+)$ L-asparagine & 22 & 15 & $68.2 \pm 6.3^{\mathrm{a}}$ \\
\hline (+) L-glutamine & 32 & 23 & $71.9 \pm 15.8^{\mathrm{a}}$ \\
\hline $\begin{array}{l}\text { (+) L-asparagine and } \\
\text { L-glutamine }\end{array}$ & 46 & 34 & $73.9 \pm 5.5^{\mathrm{a}}$ \\
\hline
\end{tabular}

\subsection{L-Asparagine and L-Glutamine Reduce Plant Defense Response by Regulating Pathogen-Related Genes}

Some soybean PRs genes were reported that they were induced by wounding and wall glucan elicitor treatment which is a pathogen-derived general defense elicitor [38,39]. To evaluate whether the plant defense response was altered with different treatments, the expression of soybean PRs, GmPR1, GmPR4, GmPR5 and GmPR10 were analyzed during co-cultivation, recovery and selection culture. 
The expression of these GmPRs in response to the treatments during different culture stage was different. The results showed that the expression of GmPR1 was weak with different treatments during co-cultivation and recovery culture, and strongly induced during selection culture in all treatments. The level of GMPR1 in treatment with no L-asparagine or L-glutamine was higher than that in other treatments with L-asparagine or/and L-glutamine. The expression level of GmPR4 was induced strongly in recovery and selection culture. The level of GmPR4 in treatment with no L-asparagine or L-glutamine was highest, and in treatment with both L-asparagine and L-glutamine it was lowest. The expression of GmPR5 has no obvious difference among treatments in co-cultivation culture, and it was obviously different between the treatment with no L-asparagine or L-glutamine and other three treatments in recovery and selection culture. The expression level of GmPR10 was the highest in treatment with no L-asparagine or L-glutamine in co-cultivation and selection culture. There was no obvious difference among treatments in recovery culture (Figure 5). The remarkable difference in expression of these GmPRs in various treatments suggested that L-asparagine and L-glutamine could play a role in mitigating plant defense responses by attenuating the expression level of GmPRs.
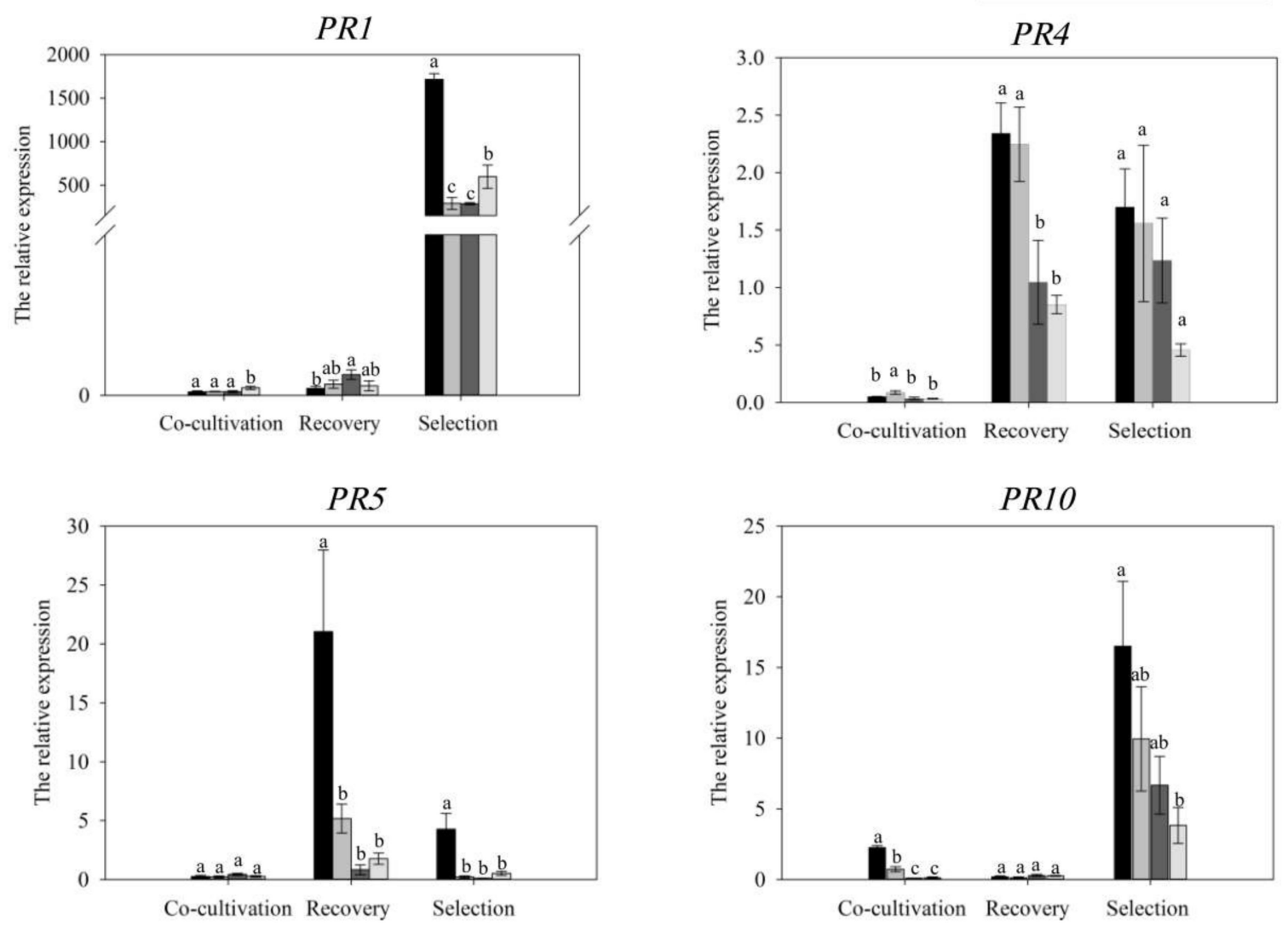

Figure 5. The expression level of GmPRsin different culture stage with treatments by qRT-PCR. The expression level of GmPR1, GmPR4, GmPR5, and GmPR10 were analyzed during co-cultivation, recovery and selection culture.GmActin was used as an internal reference. The different small letters represent significant differences between treatments by ANOVA $(p<0.05)$.

\section{Discussion}

Agrobacterium-mediated soybean transformations have been previously reported, but the transformation frequency has remained low. The effects of the great complexity of soybean 
genotypes and different explants selections on soybean transformation have been studied by different laboratories [24-27,31,32]; however, none of the reported protocols appear to be sufficient.

L-Asparagine and L-glutamine are the two major nitrogen transport compounds in most plants [40]. Under normal growth conditions, the $\mathrm{C} / \mathrm{N}$ ratio in the plant is probably the most important determining factor for whether asparagine or glutamine is selected as the major nitrogen. A high $\mathrm{C} / \mathrm{N}$ ratio can lead to the production of glutamine for nitrogen transport, and a low $\mathrm{C} / \mathrm{N}$ ratio lead to the production of asparagine for nitrogen transport [41,42]. In addition to providing carbon and nitrogen, glutamine is also involved in other cellular processes, including antioxidative stress, mTOR signalling, autophagy, and plant defence reactions [34]. The Agrobacterium-mediated transformation efficiency in perennial ryegrass (Lolium perenne L.) was highly improved by myo-inositol removal, cold shock pretreatment and L-glutamine supplementation, which enhanced Agrobacterium binding to the cell surface and decreased $\mathrm{H}_{2} \mathrm{O}_{2}$ production [34]. As the pathogen competes for host nitrogen reserves during infection, the depletion of L-glutamine in infected tissues could activate plant defence responses. In addition, a direct application of glutamine on leaves can strongly inhibit $\mathrm{H}_{2} \mathrm{O}_{2}$ production and could suppress cell death during pathogen infection [43].

In some labs, L-asparagine and L-glutamine have been added into the culture medium of at certain stages, like in shoot elongation medium or rooting medium [24,44]. However, in our study, we added the L-asparagine and/or L-glutamine from co-culture to rooting, the results showed that L-asparagine or L-glutamine added alone to culture media could enhance the regeneration rate, but better results were seen with the combination of L-asparagine and L-glutamine (Table 1). When media was supplemented with both L-asparagine and L-glutamine, the shoot induction efficiency was enhanced to $90 \%$. The elongation rate was also increased when the medium had both L-asparagine and L-glutamine; the elongation rate was above $40 \%$. For soybean, not all multiple shoots could elongate, only the elongated shoots can further grow into transformant plant. A high elongation rate is the basis for obtaining a high transformation frequency.

For the typical Jack cultivar, utilizing L-asparagine and L-glutamine in the culture medium increased the soybean transformation efficiency to approximately $11 \%$, an increase from approximately $3.5-5.5 \%$ when no asparagine or glutamine was added to the media (Tables 4 and 5). In addition, this increase in overall transformation efficiency was applicable to other soybean cultivars, with the exception of Zigongdongdou (Table 5) which for reasons unknown is relatively recalcitrant to Agrobacterium transformation. Based on this improved transformation, the soybean genome editing (CRISPR/Cas9) was successfully achieved in our lab [45]. Although the improved transformation efficiency was still not high, we can see that it has the potential to enhance the transformation efficiency by improving the positive rate of elongated shoots. At present, through this transformation process, high shoot induction and elongation rates can be achieved, and elongated shoots can be produced, although many were not positive. Further optimization of glufosinate selection may be the key factor to improving the soybean transformation efficiency.

The increased transformation efficiencies resulted in an overall larger number of $\mathrm{T} 0$ and $\mathrm{T} 1$ plants under new conditions tested. The number of inheritance transformants was 8 for no supplement versus 34 for L-asaparagine and glutamine (Table 7). A larger number of genetically stable transformants can be screened by a piece of leaf for the presence of PAT (strip tested) and confirmed through either PCR or activity of the transgene (GUS) during early seedling development. Perhaps even growing T0 seeds on selection media could help screen transformants. So the T1 plants with the desired outcome can be quickly detected from the larger number of T1 plants.

Plant defense responses can lead to cell death at the sites of Agrobacterium infection and lower transformation frequencies. Our results showed that the expression of GmPRs in various treatments was remarkable difference during co-cultivation, recovery and selection culture. The expression level of GmPRs among treatments was relative low during co-cultivation culture. The expression level of GmPR4 and GmPR5 was induced during recovery culture, but it was higher in treatment with no L-asparagine or L-glutamine than in other treatments. During selection culture, the expression level of 
GmPR1, GmPR4, GmPR5 and GmPR10 was higher in treatment with no L-asparagine or L-glutamine than in other treatments. These results suggested that L-asparagine and L-glutamine could play a role in mitigating plant defense responses by attenuating the expression level of GmPRs. The transformation frequency was enhanced in treatments with L-asparagine or/and L-glutamine. And this enhancement in transformation frequency was likely attributable to attenuation in the expression of GmPRs and suppression of plant defense response by L-asparagine and L-glutamine.

\section{Materials and Methods}

\subsection{Plant Materials}

The soybean cultivars (Jack, Zigongdongdou, Williams 82 and Heihe 27) were utilized for Agrobacterium-mediated transformation in the present study, and Jack was used for the culture medium experiments. Healthy seeds were surface-sterilized by exposure to chlorine gas for $16 \mathrm{~h}$ as described by Di [46]. Sterilized seeds were placed in germination culture medium (GCM) containing $3.1 \mathrm{~g} / \mathrm{L}$ Gamborgs Basal Salt Mixture (Phytotech, G768, Lenexa, KS, USA), 20 g/L sugar, 1mL/LGamborgs Vitamin Solution (Phytotech, G219, Lenexa, KS, USA) and $7 \mathrm{~g} / \mathrm{L}$ agar (Sigma, St. Louis, MO, USA), $\mathrm{pH} 5.8$, and the seeds were germinated at $25{ }^{\circ} \mathrm{C}$ for $18-20 \mathrm{~h}$ on the light (Figure 6a).
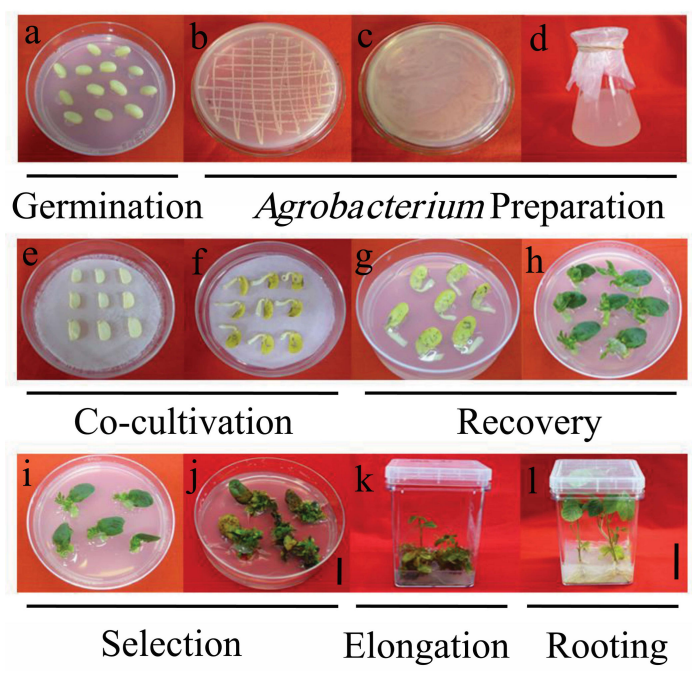

Figure 6. The process of Agrobacterium-mediated soybean half-seed transformation. (a) Germination; (b-d)Agrobacterium preparation; (e) Co-cultivation 0 day; (f) Co-cultivation 5 days; (g) Recovery 0 day; (h) Recovery 7 days; (i) Selection 0 day; (j) Selection 21 days; (k)Elongation; (1) Rooting 7 days. Scale bars, (a-j) $2.5 \mathrm{~cm} ;(\mathbf{k}, \mathbf{l}) 4 \mathrm{~cm}$.

\subsection{Agrobacterium Strain and Vector}

A. tumefaciens strain EHA101 containing the binary vector PTF102 was used in the experiments. The vector carried T-DNA containing the $\beta$-glucuronidase gene (uidA) driven by the $35 \mathrm{~S}$ CaMV promoter and the bar gene as an herbicide resistance marker [44,47].

\subsection{Agrobacterium Preparation}

Agrobacterium strain stocks of EHA101/PTF102 stored at $-80{ }^{\circ} \mathrm{C}$ were streaked on solidified YEP medium plates containing $5 \mathrm{~g} / \mathrm{L} \mathrm{NaCl}, 10 \mathrm{~g} / \mathrm{L}$ tryptone, $5 \mathrm{~g} / \mathrm{L}$ yeast extract, and $15 \mathrm{~g} / \mathrm{L}$ agar, with $50 \mathrm{mg} / \mathrm{L}$ kanamycin, $75 \mathrm{mg} / \mathrm{L}$ chloromycetin, $75 \mathrm{mg} / \mathrm{L}$ spectinomycin, and $50 \mathrm{mg} / \mathrm{L}$ rifampicin. Plates streaked with Agrobacterium were incubated at $28{ }^{\circ} \mathrm{C}$ for approximately 2 days until colony formation (Figure 6b). The colonies were collected by a spreader, daubed onto new solidified YEP medium plates with the same antibiotics and incubated overnight at $28{ }^{\circ} \mathrm{C}$ (Figure 6c). The fresh Agrobacterium were resuspended in liquid 
co-cultivation medium (LCCM) containing 1/2 Murashige\&Skoog Basal Salt Mixture (Phytotech, M524, Lenexa, KS, USA), $3.9 \mathrm{~g} / \mathrm{L} 2-(\mathrm{N}$-Morpholino) ethanesulfonic acid(MES), $30 \mathrm{~g} / \mathrm{L}$ sugar, $1 \mathrm{~mL} / \mathrm{L}$ Gamborgs Vitamin Solution, $150 \mathrm{mg} / \mathrm{L}$ DL-Dithiothreitol (DTT), $2 \mathrm{mg} / \mathrm{L}$ zeatin and $40 \mathrm{mg} / \mathrm{L}$ $3^{\prime}, 5^{\prime}$-dimethoxy-4-hydroxyacetophenone(AS), pH 5.4.Next, a final optical density of 0.6 was measured at $600 \mathrm{~nm}$, and the Agrobacterium cultures were prepared for transformation (Figure 6d).

\subsection{Infection and Co-Cultivation}

Explants were prepared from one-day-old seedlings following the method described by Paz [24]. A longitudinal cut along the hilum was made to separate the cotyledons, and the seed coat was removed. The embryonic axis found at the junctions of the hypocotyls and the cotyledon was excised to obtain the half-seed explants. The explant cuttings were immersed in Agrobacterium for $2 \mathrm{~h}$ at $50 \mathrm{rpm}$. After inoculation, each of the 9 cotyledons were placed in solid co-culture medium (CCM) containing1/2 Murashige\&Skoog Basal Salt Mixture, 3.9 g/L MES, $30 \mathrm{~g} / \mathrm{L}$ sugar, $1 \mathrm{~mL} / \mathrm{L}$ Gamborgs Vitamin Solution, $150 \mathrm{mg} / \mathrm{L}$ DTT, $40 \mathrm{mg} / \mathrm{L} \mathrm{AS}, 2 \mathrm{mg} / \mathrm{L}$ zeatinand $7 \mathrm{~g} / \mathrm{L}$ agar, $\mathrm{pH}$ 5.4, with a piece of Whatman filter paper and then incubated at $22{ }^{\circ} \mathrm{C}$ in the dark for 5 days (Figure 6e,f).

\subsection{Recovery Culture and Selection Culture}

After co-cultivation, explants were then transferred to recovery medium (SIM0) containing $3.1 \mathrm{~g} / \mathrm{L}$ Gamborgs Basal Salt Mixture, $0.98 \mathrm{~g} / \mathrm{L}$ MES, $30 \mathrm{~g} / \mathrm{L}$ sucrose, $1 \mathrm{~mL} / \mathrm{L}$ Gamborgs Vitamin Solution, $150 \mathrm{mg} / \mathrm{L}$ cefotaxime, $450 \mathrm{mg} / \mathrm{L}$ timentin, $1 \mathrm{mg} / \mathrm{L}$ 6-Benzylaminopurine (6-BA), and $7 \mathrm{~g} / \mathrm{L}$ agar, $\mathrm{pH} 5.7$, and incubated at $28^{\circ} \mathrm{C}$ for 7 days (Figure $6 \mathrm{~g}, \mathrm{~h}$ ). Seven days after recovery, the explants were transferred to selection culture medium (SIM6) containing $3.1 \mathrm{~g} / \mathrm{L}$ Gamborgs Basal Salt Mixture, $0.98 \mathrm{~g} / \mathrm{L}$ MES, $30 \mathrm{~g} / \mathrm{L}$ sucrose, $1 \mathrm{~mL} / \mathrm{L}$ Gamborgs Vitamin Solution, $150 \mathrm{mg} / \mathrm{L}$ cefotaxime, $450 \mathrm{mg} / \mathrm{L}$ timentin, $1 \mathrm{mg} / \mathrm{L} 6-\mathrm{BA}, 7 \mathrm{~g} / \mathrm{L}$ agar, and $6 \mathrm{mg} / \mathrm{L}$ glufosinate, $\mathrm{pH} 5.7$, and incubated at $28^{\circ} \mathrm{C}$ for 21 days (Figure 6i,j).

\subsection{Shoot Elongation and Rooting}

After selection culture, the cotyledons and brown leaves were cut from the explants, and the remaining tissues were transferred to shoot elongation medium (SEM) containing $4.0 \mathrm{~g} / \mathrm{L}$ Murashige\&Skoog Basal Salt Mixture, $0.6 \mathrm{~g} / \mathrm{L}$ MES, $30 \mathrm{~g} / \mathrm{L}$ sucrose, $1 \mathrm{~mL} / \mathrm{L}$ Gamborgs Vitamin Solution, $150 \mathrm{mg} / \mathrm{L}$ cefotaxime, $450 \mathrm{mg} / \mathrm{L}$ timentin, $0.1 \mathrm{mg} / \mathrm{L}$ 3-Indoleacetic acid(IAA), $0.5 \mathrm{mg} / \mathrm{L}$ Gibberellic acid(GA), $1 \mathrm{mg} / \mathrm{L}$ zeatin, $7 \mathrm{~g} / \mathrm{L}$ agar, and $6 \mathrm{mg} / \mathrm{L}$ glufosinate, $\mathrm{pH} 5.6$, and incubated at $28{ }^{\circ} \mathrm{C}$ (Figure 6k). The culture medium was changed every two weeks. Simultaneous with changing the SEM, the elongated shoots $(5-8 \mathrm{~cm})$ were cut from the base of the buds, and the stems were dipped in $1 \mathrm{mg} / \mathrm{L}$ Indole-3-Butytric acid (IBA) for $1 \mathrm{~min}$, placed ina rooting culture medium (RCM) containing 1/2 Murashige\&Skoog Basal Salt Mixture, $0.6 \mathrm{~g} / \mathrm{L}$ MES, $20 \mathrm{~g} / \mathrm{L}$ sucrose, $1 \mathrm{~mL} / \mathrm{L}$ Gamborgs Vitamin Solution, and $7 \mathrm{~g} / \mathrm{L}$ agar, $3 \mathrm{mg} / \mathrm{L}$ glufosinate, $\mathrm{pH} 5.7$, and incubated at $28^{\circ} \mathrm{C}$ for 7 days (Figure 61). After root production, the plants were transferred topots and grown in the greenhouse.

\subsection{Adding L-Asparagine and L-Glutamine}

To determine the effects of L-asparagine and L-glutamine on Agrobacterium-mediated transformation efficiency, different experimental treatments were prepared. Starting with the co-cultivation medium, L-asparagine and/or L-glutamine was added to five different medium types (CCM, SIM0, SIM6, SEM, RCM): (1) with no L-asparagine or L-glutamine; (2) with $100 \mathrm{mg} / \mathrm{L}$ L-asparagine; (3) with $100 \mathrm{mg} / \mathrm{L}$ L-glutamine; (4) with $50 \mathrm{mg} / \mathrm{L}$ L-asparagine and $50 \mathrm{mg} / \mathrm{L}$ L-glutamine.

\subsection{Detection of the Shoot Induction Rate and Elongation Rate}

During the selection stage, the shoot induction rate was calculated as follows: shoot induction rate $=$ explants with shoots $/$ total explants for infection $\times 100 \%$. During the elongation stage, 
the elongation rate was calculated as follows: elongation rate $=$ total elongated shoots $/$ total explants for infection $\times 100 \%$.

\subsection{Detection of Positive Plants and Transformation Frequency}

The transgenic plants were verified by GUS staining, leaf painting, and strip analysis. The leaf was incubated in GUS staining buffer ( $50 \mathrm{mM}$ sodium phosphate, $\mathrm{pH} 7.0,0.5 \mathrm{mM}$ potassium ferrocyanide, $0.5 \mathrm{mM}$ potassium ferricyanide, $0.5 \mathrm{mg} / \mathrm{mL}$ 5-bromo-4-chloro-3-indolyl- $\beta$-D-glucuronide (X-Gluc), $0.1 \%$ Triton X-100 and $20 \%$ methanol) for $24 \mathrm{~h}$ at $37{ }^{\circ} \mathrm{C}$ and then washed in $95 \%$ ethanol before being photographed [48]. Next, 160mg/L of glufosinate was brushed on the leaf for a leaf painting test, and Liberty Link strips were used to detect PAT proteins in the transgenic plants. The plants used to calculate transformation frequency were all positive as determined by these three detection tests. The transformation frequency was calculated as follows: transformation frequency $=$ the number of positive plants/the total explants for infection $\times 100 \%$.

\subsection{Detection of GUS Activity}

$0.1 \mathrm{~g}$ tissue samples were homogenized with $1 \mathrm{~mL}$ Phosphate buffer saline (PBS) buffer (pH 7.4) at $8000 \mathrm{rpm}$ and $4{ }^{\circ} \mathrm{C}$ for $30 \mathrm{~min}$, and the $50 \mu \mathrm{L}$ supernatant was used for the reaction. The GUS activity was measured using an enzyme-linked immunosorbent assay (ELISA) kit (SU-B91122) according to the kit instructions. The GUS ELISA Kit includes a set of calibration standards. The calibration standards are assayed at the same time as the samples and produce a standard curve of Optical Density versus GUS activity. The GUS activity (U/g) is determined by comparing the Optical Density of the samples to the standard curve generated from standard with kit.

\subsection{Plant Defence Analysis by qRT-PCR}

The expression of GmPRs was used for analysis of plant defense by qRT-PCR. The 5 days co-cultivated explants, 7 days recovery explants and 21 days selected explants were harvested for RNA extraction. Total RNA was isolated from frozen tissue using TransZolUp Plus RNA Kit (TransGen Biotech, Beijing, China). For reverse transcription, $1 \mu \mathrm{g}$ of total RNA was used to synthesize single-stranded cDNA using TransScript One-Step gDNA Removal and cDNA Synthesis SuperMix (TransGen Biotech). The GmActin gene was used as internal control. The GmPR1, GmPR4, GmPR5 and GmPR10 were used for analysis of plant defense. The primers used for GmActin amplification were 5'-GAGCTATGAATTGCCTGATGG-3' (forward) and 5'-CGTTTCATGAATTCCAGTAGC-3' (reverse). The primers used for GmPR1 amplification were $5^{\prime}$-ACACAGGTCGTTTGGGCTAA- $3^{\prime}$ (forward) and 5'-CAACAAAGTTGCCAGGGGGA-3' (reverse). The primers used for GmPR4 amplification were 5'-TGAACGCCGTGAGTGCTTAT-3' (forward) and 5'-CTGTATTCGTCACCCGGAGG-3' (reverse). The primers used for GmPR5 amplification were 5'-GTGCTTGGCGTTGAATACGG-3' (forward) and 5'-TGTGGGACACGCATTCTTGA-3' (reverse). The primers used for GmPR10 amplification were 5'-ACAACGTCATCCCAAAGGCT-3' (forward) and $5^{\prime}$-TCCATTCATTAACATCAGCCTCA-3' (reverse). qRT-PCR reactions were performed according to the three-step method using SYBR Green I dye and the ABI7500 instrument for qRT-PCR. For qRT-PCR, a total volume of $20 \mu \mathrm{L}$ was used that contained $10 \mu \mathrm{L}$ of SYBR Premix Ex Taq $(2 \times), 0.4 \mu \mathrm{L}$ of dye, $0.4 \mu \mathrm{L}$ of $10 \mu \mathrm{M}$ of the upstream or downstream primers, $2 \mu \mathrm{L}$ of cDNA template, and $6.8 \mu \mathrm{L}$ of $\mathrm{ddH}_{2} \mathrm{O}$. qRT-PCR amplification using the standard three-step procedure for denaturation was performed as follows: $95^{\circ} \mathrm{C}$ for $30 \mathrm{~s}$, followed by 40 cycles of $95^{\circ} \mathrm{C}$ for $5 \mathrm{~s}$, and $60^{\circ} \mathrm{C}$ for $30 \mathrm{~s}$. The relative expression level was calculated using the comparative $2^{-\Delta \Delta C t}$ method.

\subsection{Molecular Analysis}

PCR, strip and southern blot were used to analysis T1 generations of transgenic lines. Total genomic DNA was extracted from the leaves of the T1 transgenic plants using CTAB method. The bar gene detection in transgenic plants was demonstrated by PCR amplification 
of a $427 \mathrm{bp}$ fragment using the primer pair $5^{\prime}$-GCACCATCGTCAACCACTACATC- $3^{\prime}$ and $5^{\prime}$-CAGAAACCCACGTCATGCCAGTT-3'. For southern blot analysis, the $10 \mu \mathrm{g}$ genomic DNA was digested with HindIII, the restriction products were separated on $0.8 \%$ agarose gel and transferred onto a nylon Hybond- $\mathrm{N}^{+}$membrane (Roche, Mannheim, Germany) with a membrane transfer instrument (Model 785, Bio-Rad, Hercules, CA, USA). The bar (427 bp) PCR products were labelled with Digoxigenin and used as probes to hybridize with the digested DNA on the membrane. The hybridization and detection steps were performed according to the instructions for the DIG High Prime DNA Labeling and Detection Starter KitII (Roche, Mannheim, Germany).

\subsection{Statistical Analysis}

For all experiments, each treatment contained three replicates. The regeneration frequency, elongation rate and transformation frequency were expressed as the mean \pm standard deviation, and the data shown represent the mean of three independent experiments. The data were analysed by ANOVA. The different small letters represent significant differences at $p<0.05$.

\section{Conclusions}

Adding $50 \mathrm{mg} / \mathrm{L} \mathrm{L}$-asparagine and $50 \mathrm{mg} / \mathrm{L}$ L-glutamine in culture medium enhanced shoot induction frequency and elongation rate in soybean transformation and finally improved the transformation frequency. The transformation frequency of Jack increased from a baseline of approximately $3.5-5.5 \%$ to $11 \%$ in the presence of both L-aparagine and L-glutamine. In addition, the improved conditions can be applied to more soybean cultivars. L-asparagine and L-glutamine could play a role in mitigating plant defense responses by attenuating the expression level of GmPRs. The enhancement in transformation frequency was likely attributable to attenuation in the expression of GmPRs and suppression of plant defense response. The transgene can be successfully transmitted to the T1 generation. This study may be useful in genetic engineering of soybean.

Author Contributions: Conceptualization, W.H.; Data curation, L.C. and Y.C.; Formal analysis, X.L. and C.G.; Funding acquisition, L.C., T.H. and W.H.; Investigation, W.Y.; Project administration, L.C. and W.H.; Resources, S.S., C.W. and B.J.; Supervision, W.H.; Validation, L.C. and Y.C.; Visualization, L.C. and Y.C.; Writing-original draft, L.C. and Y.C.; Writing-review \& editing, T.H. and W.H.

Acknowledgments: This work was supported by the Major Science and Technology Projects of China (2016ZX08010-004), the Ministry of Science and Technology of China (2016YFD0100504), the National Natural Science Foundation of China (31471571, 31601327), the Basic Research Program of the Chinese Academy of Agricultural Sciences (Y2017XM03).

Conflicts of Interest: The authors declare no conflict of interest.

\section{Abbreviations}

$\begin{array}{ll}\text { GCM } & \text { germination culture medium } \\ \text { LCCM } & \text { liquid co-cultivation medium } \\ \text { CCM } & \text { co-culture medium } \\ \text { SIM0 } & \text { recovery medium } \\ \text { SIM6 } & \text { selection culture medium } \\ \text { SEM } & \text { shoot elongation medium } \\ \text { RCM } & \text { rooting culture medium } \\ \text { MES } & \text { 2-(N-morpholino)ethanesulfonic acid } \\ \text { DTT } & \text { DL-dithiothreitol } \\ \text { AS } & \text { 3', } 5^{\prime} \text {-dimethoxy-4-hydroxyacetophenone } \\ \text { 6-BA } & \text { 6-benzylaminopurine } \\ \text { GA } & \text { gibberellic acid } \\ \text { IAA } & \text { 3-indoleacetic acid } \\ \text { IBA } & \text { indole-3-butytric acid }\end{array}$




\section{References}

1. Homrich, M.S.; Wiebke-Strohm, B.; Weber, R.L.; Bodanese-Zanettini, M.H. Soybean genetic transformation: A valuable tool for the functional study of genes and the production of agronomically improved plants. Genet. Mol. Biol. 2012, 35, 998-1010. [CrossRef] [PubMed]

2. James, C. 20th Anniversary (1996 to 2015) of the Global Commercialization of Biotech Crops and Biotech Crop Highlights in 2015; International Service for the Acquisition of Agri-biotech Applications: Ithaca, NY, USA, 2015; Brief No.51.

3. Xia, Z.; Zhai, H.; Lü, S.; Wu, H.; Zhang, Y. Recent achievement in gene cloning and functional genomics in soybean. Sci. World J. 2013, 2013, 281367. [CrossRef] [PubMed]

4. Shan, Q.; Wang, Y.; Li, J.; Zhang, Y.; Chen, K.; Liang, Z.; Zhang, K.; Liu, J.; Xi, J.J.; Qiu, J.L.; et al. Targeted genome modification of crop plants using a CRISPR-Cas system. Nat. Biotechnol. 2013, 31, 686-688. [CrossRef] [PubMed]

5. Jiang, W.; Zhou, H.; Bi, H.; Fromm, M.; Yang, B.; Weeks, D.P. Demonstration of CRISPR/Cas9/sgRNA-mediated targeted gene modification in Arabidopsis, tobacco, sorghum and rice. Nucleic Acids Res. 2013, 41, e188. [CrossRef] [PubMed]

6. Feng, Z.; Zhang, B.; Ding, W.; Liu, X.; Yang, D.L.; Wei, P.; Cao, F.; Zhu, S.; Zhang, F.; Mao, Y.; et al. Efficient genome editing in plants using a CRISPR/Cas system. Cell Res. 2013, 23, 1229-1232. [CrossRef] [PubMed]

7. Miao, J.; Guo, D.; Zhang, J.; Huang, Q.; Qin, G.; Zhang, X.; Wan, J.; Gu, H.; Qu, L.J. Targeted mutagenesis in rice using CRISPR-Cas system. Cell Res. 2013, 23, 1233-1236. [CrossRef] [PubMed]

8. Xie, K.; Zhang, J.; Yang, Y. Genome-wide prediction of highly specific guide RNA spacers for CRISPR-Cas9-mediated genome editing in model plants and major crops. Mol. Plant 2014, 7, 923-926. [CrossRef] [PubMed]

9. Upadhyay, S.K.; Kumar, J.; Alok, A.; Tuli, R. RNA-guided genome editing for target gene mutations in wheat. G3 2013, 3, 2233-2238. [CrossRef] [PubMed]

10. Wang, Y.; Cheng, X.; Shan, Q.; Zhang, Y.; Liu, J.; Gao, C.; Qiu, J.L. Simultaneous editing of three homoeoalleles in hexaploid bread wheat confers heritable resistance to powdery mildew. Nat. Biotechnol. 2014, 32, 947-951. [CrossRef] [PubMed]

11. Liang, Z.; Zhang, K.; Chen, K.; Gao, C. Targeted mutagenesis in Zea mays using TALENs and the CRISPR/Cas system. J. Genet. Genom. 2014, 41, 63-68. [CrossRef] [PubMed]

12. Svitashev, S.; Young, J.K.; Schwartz, C.; Gao, H.; Falco, S.C.; Cigan, A.M. Targeted mutagenesis, precise gene editing, and site-specific gene Insertion in maize using Cas9 and guide RNA. Plant Physiol. 2015, 169, 931-945. [CrossRef] [PubMed]

13. Jacobs, T.B.; LaFayette, P.R.; Schmitz, R.J.; Parrott, W.A. Targeted genome modifications in soybean with CRISPR/Cas9. BMC Biotechnol. 2015, 15, 16. [CrossRef] [PubMed]

14. Sun, X.; Hu, Z.; Chen, R.; Jiang, Q.; Song, G.; Zhang, H.; Xi, Y. Targeted mutagenesis in soybean using the CRISPR-Cas9 system. Sci. Rep. 2015, 5, 10342. [CrossRef] [PubMed]

15. Cai, Y.; Chen, L.; Liu, X.; Sun, S.; Wu, C.; Jiang, B.; Han, T.; Hou, W. CRISPR/Cas9-mediated genome editing in soybean hairy roots. PLoS ONE 2015, 10, e0136064. [CrossRef] [PubMed]

16. Li, Z.; Liu, Z.B.; Xing, A.; Moon, B.P.; Koellhoffer, J.P.; Huang, L.; Ward, R.T.; Clifton, E.; Falco, S.C.; Cigan, A.M. Cas9-Guide RNA Directed Genome Editing in Soybean. Plant Physiol. 2015, 169, 960-970. [CrossRef] [PubMed]

17. Michno, J.M.; Wang, X.; Liu, J.; Curtin, S.J.; Kono, T.J.; Stupar, R.M. CRISPR/Cas mutagenesis of soybean and Medicagotruncatula using a new web-tool and a modified Cas9 enzyme. GM Crops Food 2015, 6, $243-252$. [CrossRef] [PubMed]

18. Tang, F.; Yang, S.; Liu, J.; Zhu, H. Rj4, a gene controlling nodulation specificity in soybeans, encodes a thaumatin-like protein but not the one previously reported. Plant Physiol. 2016, 170, 26-32. [CrossRef] [PubMed]

19. Du, H.; Zeng, X.; Zhao, M.; Cui, X.; Wang, Q.; Yang, H.; Cheng, H.; Yu, D. Efficient targeted mutagenesis in soybean by TALENs and CRISPR/Cas9. J. Biotechnol. 2016, 217, 90-97. [CrossRef] [PubMed] 
20. Hinchee, M.A.; Connor-Ward, D.V.; Newell, C.A.; McDonell, R.E.; Sato, S.J.; Gasser, C.S.; Fishhoff, D.A.; Re, D.B.; Fraley, R.T.; Horsch, R.B. Production of transgenic soybean plants using Agrobacterium-mediated DNA transfer. Nat. Biotechnol. 1988, 6, 915-922. [CrossRef]

21. McCabe, D.E.; Swain, W.F.; Martinell, B.J.; Christou, P. Stable transformation of soybean (Glycine max) by particle acceleration. Nat. Biotechnol. 1988, 6, 923-926. [CrossRef]

22. Shri, M.; Rai, A.; Verma, P.K.; Misra, P.; Dubey, S.; Kumar, S.; Verma, S.; Gautam, N.; Tripathi, R.D.; Trivedi, P.K.; et al. An improved Agrobacterium-mediated transformation of recalcitrant indica rice (Oryza sativa L.) cultivars. Protoplasma 2013, 250, 631-636. [CrossRef] [PubMed]

23. Cheng, M.; Lowe, B.A.; Spencer, T.M.; Ye, X.D.; Armstrong, C.L. Factors influencing Agrobacterium-mediated transformation of monocotyledonous species. In Vitro Cell. Dev. Biol-Plant 2004, 40, 31-45. [CrossRef]

24. Paz, M.M.; Martinez, J.C.; Kalvig, A.B.; Fonger, T.M.; Wang, K. Improved cotyledonary node method using an alternative explants derived from mature seed for efficient Agrobacterium-mediated soybean transformation. Plant Cell Rep. 2006, 25, 206-213. [CrossRef] [PubMed]

25. Wang, G.; Xu, Y. Hypocotyl-based Agrobacterium-mediated transformation of soybean (Glycine max) and application for RNA interference. Plant Cell Rep. 2008, 27, 1177-1184. [CrossRef] [PubMed]

26. Liu, H.K.; Yang, C.; Wei, Z.M. Efficient Agrobacterium tumefaciens-mediated transformation of soybeans using an embryonic tip regeneration system. Planta 2004, 219, 1042-1049. [CrossRef] [PubMed]

27. Meurer, C.A.; Dinkins, R.D.; Collins, G.B. Factors affecting soybean cotyledonary node transformation. Plant Cell Rep. 1998, 18, 180-186. [CrossRef]

28. Zhang, Z.; Xing, A.; Staswick, P.E.; Clemente, T.E. The use of glufosinate as a selective agent in Agrobacterium-mediated transformation of soybean. Plant Cell Tissue Organ. Cult. 1999, 56, 37-46. [CrossRef]

29. Clemente, T.E.; LaVallee, B.J.; Howe, A.R.; Conner-Ward, D.; Rozman, R.J.; Hunter, P.E.; Broyles, D.L.; Kasten, D.S.; Hinchee, M.A. Progeny analysis of glyphosate selected transgenic soybean derived from Agrabacterium-mediated transformation. Crop Sci. 2000, 40, 797-803. [CrossRef]

30. Olhoft, P.M.; Flagel, L.E.; Donovan, C.M.; Somers, D.A. Efficient soybean transformation using hygromycin B selection in the cotyledonary-node method. Planta 2003, 216, 723-735. [PubMed]

31. Liu, S.J.; Wei, Z.M.; Huang, J.Q. The effect of co-cultivation and selection parameters on Agrobacterium-mediated transformation of Chinese soybean varieties. Plant Cell Rep. 2008, 27, 489-498. [CrossRef] [PubMed]

32. Arun, M.; Subramanyam, K.; Mariashibu, T.S.; Theboral, J.; Shivanandhan, G.; Manickavasagam, M.; Ganapathi, A. Application of sonication in combination with vacuum infiltration enhances the Agrobacterium-mediated genetic transformation in India soybean cultivars. Appl. Biochem. Biotechnol. 2015, 175, 2266-2287. [CrossRef] [PubMed]

33. Zeng, P.; Vadnais, D.A.; Zhang, Z.; Polacco, J.C. Refined glufosinate selection in Agrobacterium-mediated transformation of soybean [Glycine $\max$ (L.) Merrill]. Plant Cell Rep. 2004, 22, 478-482. [CrossRef] [PubMed]

34. Zhang, W.J.; Dewey, R.E.; Boss, W.; Phillippy, B.Q.; Qu, R. Enhanced Agrobacterium-mediated transformation efficiencies in monocot cells is associated with attenuated defense responses. Plant Mol. Biol. 2013, 81, 273-286. [CrossRef] [PubMed]

35. Wu, C.C.; Singh, P.; Chen, M.C.; Zimmerli, L. L-Glutamine inhibits beta-aminobutyric acid-induced stress resistance and priming in Arabidopsis. J. Exp. Bot. 2010, 61, 995-1002. [CrossRef] [PubMed]

36. Pageau, K.; Reisdorf-Cren, M.; Morot-Gaudry, J.F.; Masclaux-Daubresse, C. The two senescence-related markers, GSI and GDH, involved in nitrogen mobilization, are differentially regulated during pathogen attack and by stress hormones and reactive oxygen species in Nicotianatabacum L. leaves. J. Exp. Bot. 2006, 57, 547-557. [CrossRef] [PubMed]

37. Zhang, J.; Fan, J.; Venneti, S.; Cross, J.R.; Takagi, T.; Bhinder, B.; Djaballah, H.; Kanai, M.; Cheng, E.H.; Judkins, A.R.; et al. Asparagine plays a critical role in regulating cellular adaptation to glutamine depletion. Mol. Cell 2014, 56, 205-218. [CrossRef] [PubMed]

38. Graham, M.Y.; Weidner, J.; Wheeler, K.; Pelow, M.J.; Graham, T.L. Induced expression of pathogenesis-related protein genes in soybean by wounding and the Phytophthorasojae cell wall glucan elicitor. Physiol. Mol. Plant P. 2003, 63, 141-149. [CrossRef]

39. Graham, M.Y. The diphenylether herbicide lactofen induces cell death and expression of defense-related genes in soybean. Plant Physiol. 2005, 139, 1784-1794. [CrossRef] [PubMed] 
40. Møller, M.G.; Taylor, C.; Rasmussen, S.K.; Holm, P.B. Molecular cloning and characterization of two genes encoding asparagine synthetase in barly (Hordeumvulgare L.). Biochim. Biophys. Acta 2003, 1628, 123-132.

41. Lam, H.M.; Coschigano, K.; Schultz, C.; Melo-Oliveria, R.; Tjaden, G.; Oliveira, I.; Ngai, N.; Hsieh, M.H.; Coruzzi, G. Use of Arabidopsis mutants and genes to study amide amino acid biosynthesis. Plant Cell 1995, 7, 887-898. [CrossRef] [PubMed]

42. Lam, H.M.; Peng, S.S.; Coruzzi, G.M. Metabolic regulation of the gene encoding glutamine-dependent asparagine synthetase in Arabidopsis thaliana. Plant Physiol. 1994, 106, 1347-1357. [CrossRef] [PubMed]

43. Liu, G.; Ji, Y.; Bhuiyan, N.H.; Pilot, G.; Selvaraj, G.; Zou, J.; Wei, Y. Amino acid homeostasis modulates salicylic acid-associated redox status and defense responses in Arabidopsis. Plant Cell 2010, 22, 3845-3863. [CrossRef] [PubMed]

44. Song, Z.Y.; Tian, J.L.; Fu, W.Z.; Li, L.; Lu, L.H.; Zhou, L.; Shan, Z.H.; Tang, G.X.; Shou, H.X. Screening Chinese soybean genotypes for Agrobacterium-mediated genetic transformation suitability. J. ZhejiangUniv. Sci. B. 2013, 14, 289-298. [CrossRef] [PubMed]

45. Cai, Y.; Chen, L.; Liu, X.; Guo, C.; Sun, S.; Wu, C.; Jiang, B.; Han, T.; Hou, W. CRISPR/Cas9-mediated targeted mutagenesis of GmFT2a delays flowering time in soya bean. Plant Biotechnol. J. 2018, 16, 176-185. [CrossRef] [PubMed]

46. Di, R.; Purcell, V.; Collins, G.B.; Ghabril, S.A. Production of transgenic soybean lines expressing the bean pod mottle virus coat protein precursor gene. Plant Cell Rep. 1996, 15, 746-750. [CrossRef] [PubMed]

47. Frame, B.R.; Shou, H.X.; Chikwamba, R.K.; Zhang, Z.; Xiang, C.; Fonger, T.M.; Pegg, S.E.K.; Li, B.; Nettleton, D.S.; Pei, D.; et al. Agrobacterium tumefaciens-mediated transformation of maize embryos using standard binary vector system. Plant Physiol. 2002, 129, 13-22. [CrossRef] [PubMed]

48. Jefferson, R.A. Assaying chimeric genes in plants: The GUS gene fusion system. Plant Mol. Biol. Rep. 1987, 5, 387-405. [CrossRef]

(C) 2018 by the authors. Licensee MDPI, Basel, Switzerland. This article is an open access article distributed under the terms and conditions of the Creative Commons Attribution (CC BY) license (http:/ / creativecommons.org/licenses/by/4.0/). 